\title{
UMA NOVA MODALIDADE DE REMIÇÃO DA PENA: ALTERNATIVA AO DEVER DE INDENIZAR DO ESTADO
}

\author{
Igor Cezar Abdala Marini, Fábio Ferreira Morong \\ Universidade do Oeste Paulista - UNOESTE, curso de Direito, Presidente Prudente, SP. E-mail: \\ igor abdalaadv@hotmail.com; fabiomorong@hotmail.com
}

\section{RESUMO}

Este trabalho tem como objetivo demostrar que a remição de pena em razão do seu cumprimento em estabelecimento inadequado é uma medida eficaz, que melhor atende o princípio da dignidade da pessoa humana, bem como, revelar como esse instituto pode contribuir para a não oneração do erário público. Justifica-se que o mesmo Estado que proíbe penas cruéis deve ser responsabilizado objetivamente pela omissão que ocorre em presídios com condições degradantes e desumanas. O método aplicado foi o dedutivo legal com a análise da doutrina, legislação nacional e jurisprudência pertinente ao tema. Conclui-se que essa nova modalidade de remição parece ser uma nova evolução legislativa e prática para o Direito Penal Brasileiro, que trará benefícios para o condenado e também para o Estado, que ficará isento das indenizações, enfatizando desde já que este novo critério de remição não pode servir de escusa e fundamento para o Estado não investir em melhorias no sistema prisional.

Palavras-chave: penas cruéis, estabelecimentos prisionais, superlotação carcerária, remição de penas, responsabilidade objetiva do Estado.

\section{A NEW REMEDY OF THE PEN: ALTERNATIVE TO THE OBLIGATION TO INDEMNIFY THE STATE}

\section{ABSTRACT}

The purpose of this study is to show that the remission of punishment due to its fulfillment in an inadequate establishment is an effective measure that best meets the principle of the dignity of the human person, as well as reveal how this institute can contribute to the non-encumberment of the treasury public. It is justified that the same State which prohibits cruel punishment must be held liable for the omission occurring in prisons with degrading and inhuman conditions. The applied method was the legal deductive with the analysis of the doctrine, national legislation and relevant jurisprudence on the subject.

Keywords: Cruel punishment, prisons, overcrowding, remission of sentences, objective State responsibility.

\section{INTRODUÇÃO}

O tema desenvolvido trata-se de uma alternativa para o Direito Penal Brasileiro, a criação de um novo benefício na execução da pena em razão da responsabilidade objetiva do Estado.

Pretende se criar uma nova modalidade de remição da pena atrelada as condições ambientais do lugar onde se cumpre a reprimenda. No Brasil, o Estado é o responsável pelos estabelecimentos prisionais, inclusive sob pena de pagamento de indenização em casos de descumprimento às condições mínimas de humanidade, por exemplo, superlotação carcerária.

A justificativa se dá em razão do Estado contar com um déficit de vagas prisionais muito grande, e também porque não é um ente detentor de recursos suficientes para garantir indenizações, portanto, a criação de um novo benefício de remição de penas pautado nessas 
condições passa a ser uma alternativa para o Direito Penal Brasileiro, que entre outras palavras, atenderá tanto os anseios do apenado, como também do Estado.

O objetivo, portanto, é mostrar que a remição de pena em razão do seu cumprimento em estabelecimento inadequado é uma medida eficaz, que melhor atende o princípio da dignidade da pessoa humana, bem como, revelar como esse instituto pode contribuir para a não oneração do erário público.

\section{METODOLOGIA}

Para elaboração do presente trabalho utilizou-se da metodologia da pesquisa bibliográfica, utilizando materiais como doutrinas, legislação nacional e jurisprudências, que são pertinentes para o objeto em estudo. O método dedutivo também fora utilizado para sistematizar os dados coletados a fim de cumprir o objetivo proposto.

\section{DA PROIBIÇÃO DE PENAS CRUÉIS, DESUMANAS OU DEGRADANTES}

Um dos princípios fundamentais basilares da Constituição Federal é o princípio da dignidade da pessoa humana. Este princípio deve ser respeitado em todas as esferas do Direito, especialmente no Direito Penal que trata da liberdade do cidadão.

Daí por que toda lei que viole a dignidade da pessoa humana deve ser reputada como inconstitucional. Assim, pode-se afirmar que, "se o Direito não quiser ser mera força, mero terror, se quiser obrigar a todos os cidadãos em sua consciência, há de respeitar a condição do homem como pessoa, como ser responsável", pois, "no caso de infração grave ao princípio material de justiça, de validade a priori, ao respeito à dignidade da pessoa humana, carecerá de força obrigatória e, dada sua injustiça, será preciso negar-Ihe o caráter de Direito". (PRADO, 2014, p.79).

A imposição de pena no Direito Penal tem passado por várias evoluções, desde as penas capitais até as penas atuais. Essa evolução acompanha o despertar humanitário do cidadão e passou a ser largamente estabelecidos em documentos e tratados internacionais, que obrigam os Estados signatários a observa-los.

Neste sentido se encontra a Declaração dos Direitos do Homem (1948) que diz em seus artigos III e V: "todo indivíduo tem direito à vida, à liberdade e à segurança pessoal [...]; ninguém será submetido a tortura, nem a tratamento ou castigo cruel, desumano ou degradante". Também pode-se citar o Pacto Internacional dos Direitos Civil e Políticos (1966), Convenção contra a Tortura e outros Tratamentos ou Penas Cruéis, Desumanos ou Degradantes (1984), entre outros.

Com isto a Constituição Federal elencou em seu artigo 5o vários incisos tratando respectivamente do assunto. Pode-se dizer, portanto, que esta característica fez nascer o princípio da humanidade, que proíbe a criação, a aplicação ou a execução de pena em situações desumanas ou degradantes.

O princípio da humanidade do Direito Penal é o maior entrave para a adoção de pena capital e da prisão perpétua. Esse princípio sustenta que o poder punitivo estatal não pode aplicar sanções que atinjam a dignidade da pessoa humana ou que lesionem a constituição físico-psíquica dos condenados. A proscrição de penas cruéis e infamantes, a proibição de tortura e maus-tratos nos interrogatórios policiais e a obrigação imposta ao Estado de dotar sua infraestrutura carcerária de meios e recursos que impeçam a degradação e a dessocialização dos condenados são corolários do princípio da humanidade. (BITENCOURT, 2017, p.73) 
Seguindo ainda o princípio da humanidade ainda pode-se destacar:

Apresenta-se como uma diretriz garantidora de ordem material e restritiva da lei penal, verdadeira salvaguarda da dignidade pessoal, relacionando-se de forma estreita com os princípios da culpabilidade e da igualdade. A Constituição estabelece como fundamento do Estado democrático de Direito a dignidade da pessoa humana (art. 10, III, CF), dispondo, ainda, expressamente, que "a lei punirá qualquer discriminação atentatória dos direitos e liberdades fundamentais" (art. 5ㅇ, XLI, CF); "não haverá penas: a) de morte, salvo em caso de guerra declarada, nos termos do art. 84, XIX; b) de caráter perpétuo; c) de trabalhos forçados; d) de banimento; e) cruéis" (art. 50, XLVII, CF); "é assegurado aos presos o respeito à integridade física e moral" (art. 5, XLIX, CF). (PRADO, 2014, p.59)

Se o Estado não respeitar esses princípios irá ocorrer um retrocesso a uma era já superada. Vale lembrar das indagações realizadas por Carnelutti (2013, p.72), num passado não muito distante, a respeito das misérias do processo penal, que chegou a comparar a penitenciária a um cemitério, porém, com uma ressalva, "o condenado é um sepultado vivo".

A adequação do sistema prisional é necessária para a garantia da ressocialização do apenado, aliás, esta é a finalidade primordial da pena. E de acordo com a Criminologia Moderna, uma das formas de prevenção do delito esta diretamente ligada à população carcerária, a chamada prevenção terciária: "A prevenção terciária se destina única e exclusivamente ao condenado. Tem como objetivo evitar a reincidência. Aqui, a ressocialização do criminoso é voltada apenas para o infrator no ambiente carcerário" (SUMARIVA, 2017, p.159).

Portanto, no atual Estado Democrático de Direito é terminantemente proibida a execução de pena cruel, desumana ou degradante, tendo em vista que atenta contra a dignidade da pessoa humana e à ressocialização do condenado.

\section{DA RESPONSABILIDADE OBJETIVA DO ESTADO}

A responsabilidade objetiva do Estado quanto à prática de conduta comissiva já se encontra superada pela doutrina e jurisprudência. $O$ grande entrave diz respeito à conduta omissiva do Estado, seria esta apta a desencadear a responsabilidade objetiva?

[...] a omissão configura a culpa in omittendo ou in vigilando. São casos de inércia, casos de não atos. Se cruza os braços ou se não vigia, quando deveria agir, o agente público omite-se, empenhando a responsabilidade do Estado por inércia ou incúria do agente. Devendo agir não agiu. Nem como o 'bonus pater familiae', nem como o 'bonus administrador'. Foi negligente, às vezes imprudente e até imperito. Negligente, se a solércia o dominou; imprudente, se confiou na sorte; imperito, se não previu as possibilidades da concretização do evento. Em todos os casos, culpa, ligada à ideia de inação, física ou mental. (CRETELLA JÚNIOR, 1970 apud DI PIETRO, 2017, p.827)

A responsabilidade objetiva seria aquela capaz de gerar o dever de indenizar independentemente de dolo ou culpa, ação ou omissão, e a respeito deste tema ainda temos que:

No caso de omissão do Poder Público os danos em regra não são causados por agentes públicos. São causados por fatos da natureza ou fatos de 
terceiros. Mas poderiam ter sido evitados ou minorados se o Estado, tendo o dever de agir, se omitiu. (DI PIETRO, 2017, p.828)

Sendo assim, a responsabilidade do Estado em casos de superlotação carcerária e relativa às condições do presídio deve ser analisada como uma responsabilidade objetiva, uma vez que há flagrante omissão aos padrões mínimos de humanidade consagrados pela própria Constituição Federal, gerando o dever de indenizar.

Ademais estabelece o artigo $37 \S 60$, da Constituição Federal que o dano deverá ser suportado pelo Estado, independentemente do agente público ter agido com dolo ou culpa. Embora, divergente, a jurisprudência "tem entendido que a atividade administrativa a que alude o art. 37, $\S 60$, da Constituição Federal abrange tanto a conduta comissiva como a omissiva" (GONÇALVES, 2017, p.166).

Seguindo este critério pode-se apontar dois julgados que deixam clara a responsabilidade objetiva do Estado em casos de omissão dentro do sistema carcerário. O primeiro seria uma decisão do STJ através do Recurso Especial - REsp 1.305.259-SC, e o segundo uma decisão do STF, reconhecendo a repercussão geral, no Recurso Extraordinário - RE 580252.

No primeiro caso a jurisprudência reconheceu a responsabilidade objetiva do Estado no caso de suicídio de um detento dentro do estabelecimento prisional, tendo em vista que a Administração Pública é responsável pela integridade física dos presidiários:

DIREITO ADMINISTRATIVO. RESPONSABILIDADE OBJETIVA DO ESTADO NO CASO DE SUICÍDIO DE DETENTO. A Administração Pública está obrigada ao pagamento de pensão e indenização por danos morais no caso de morte por suicídio de detento ocorrido dentro do estabelecimento prisional mantido pelo Estado. Nessas hipóteses, não é necessário perquirir eventual culpa da Administração Pública. Na verdade, a responsabilidade civil estatal pela integridade dos presidiários é objetiva em face dos riscos inerentes ao meio no qual foram inseridos pelo próprio Estado. Assim, devem ser reconhecidos os referidos direitos em consideração ao disposto nos arts. 927, parágrafo único, e 948, II do CC. (BRASIL, 2013).

Na segunda jurisprudência, onde se discute a responsabilidade civil do Estado por danos morais decorrentes de superlotação carcerária, o STF reconheceu a repercussão geral do tema, que encontra-se cadastrado sob o no 365 com a seguinte tese:

Considerando que é dever do Estado, imposto pelo sistema normativo, manter em seus presídios os padrões mínimos de humanidade previstos no ordenamento jurídico, é de sua responsabilidade, nos termos do art. $37, \S$ 60, da Constituição, a obrigação de ressarcir os danos, inclusive morais, comprovadamente causados aos detentos em decorrência da falta ou insuficiência das condições legais de encarceramento. (STF, 2017, s/p).

Portanto, seguindo a doutrina e a jurisprudência, a responsabilidade do estado é objetiva em relação às condições carcerárias, notadamente, sobre a questão da superlotação.

\section{UM NOVO CRITÉRIO DE REMIÇÃO DE PENAS}

De acordo com o CNJ (2014), atualmente o Brasil ocupa a quarta posição no ranking dos 10 países com maior população prisional, ficando atrás dos Estados Unidos da América, que ocupa a primeira colocação; China; e Rússia, que ocupa o terceiro lugar.

O mesmo estudo ainda aponta que a população no sistema prisional (excluída a prisão domiciliar) alcança o número de 563.526 presos, sendo que a capacidade do sistema conta com 
357.219 vagas. Só aí é possível observar um déficit de vagas de 206.307. O número de mandados de prisão em aberto também causa espanto, chegando a quantidade de 373.991.

Essa realidade torna-se preocupante e revela que o Estado não se encontra preparado para cumprir com a ressocialização da pena, uma vez que pela simples analise aritmética é possível observar a incidência de superlotação carcerária.

É possível notar ainda que essa nova vertente pode acabar abrindo um leque de ações contra a Administração Pública pretendendo a indenização por danos morais, pois se encontram desrespeitadas as regras mínimas de humanidade. Isso colocaria o Estado em colapso, uma vez que não conta com recursos suficientes para despender tais indenizações.

Como forma de auxiliar o problema, pretende-se a criação de uma nova modalidade de remição de penas, pois este instituto seria eficaz para o preso, que teria parte da sua pena remida ao invés de ficar com um crédito perante o Estado, e da mesma forma não oneraria o erário público, que poderia utilizar esse dinheiro para melhoria do próprio sistema.

Essa questão foi suscitada pelo ministro Luís Roberto Barroso no julgamento do RE 580252. O ministro em seu voto destacou o Direito comparado e a aplicação por analogia do artigo 126 da Lei de Execução Penal:

Ao propor essa forma alternativa de reparação do dano moral sofrido, o ministro explicou que o pagamento de indenizações pecuniárias não resolve o problema nem do indivíduo nem do sistema, podendo mesmo agregar complicações, já que não foram estabelecidos quaisquer critérios. Além disso, eventual decisão do STF confirmando a possibilidade de indenização pecuniária abriria outro flanco grave: a deflagração de centenas de milhares de ações em diferentes estados do Brasil, de presos requerendo indenizações. O ministro citou a Itália como exemplo de país que adotou soluções alternativas para o problema da superpopulação carcerária. Lá, segundo Roberto Barroso, foi implantada uma solução sistêmica, que previu a adoção de medidas cautelares alternativas diversas da prisão, a prisão domiciliar para crimes de menor potencial ofensivo e a monitoração eletrônica, entre outros. E, também, a possibilidade de remição de um dia de pena para cada dez dias de detenção em condições degradantes ou desumanas. (STF, 2015, p.1).

A remição de pena "é o desconto do tempo de pena privativa de liberdade pelo trabalho ou estudo, na proporção de três dias trabalhados ou de estudo por um dia de pena (art. 126, § 1으, I e II, LEP)", conforme ensina Nucci (2015, p.982).

Remir significa resgatar, abater, descontar, pelo trabalho realizado dentro do sistema prisional, parte do tempo de pena a cumprir [...]. Significa que, pelo trabalho (agora também pelo estudo), o condenado fica desobrigado de cumprir determinado tempo de pena. Remição com "ç" (desobrigação, resgate) não se confunde com remissão com "ss", que tem o significado de perdão. (BITENCOURT, 2017, p.654).

Neste ponto, criar-se-ia um novo critério de remição de pena vinculado ao estabelecimento prisional e as suas condições de habitação. O cumprimento de pena em estabelecimento inadequado pode acarretar um dano moral e psíquico no apenado, sendo que um dia de cumprimento nessas características pode ser o equivalente a três dias de pena se fosse cumprida em um estabelecimento adequado. 


\section{CONCLUSÃO}

O Estado, além da obrigação de punir o infrator, tem a obrigação de ressocializa-lo, e isto significa colocar a disposição do preso estabelecimentos prisionais adequados para o cumprimento de pena em decorrência do princípio da humanidade, corolário do princípio da dignidade da pessoa humana.

A violação a esse dever faz com que o Estado seja responsabilizado civilmente pela omissão, podendo responder pelos danos morais que tiver causado, tendo que despender um valor pecuniário que não detém. E pela defasagem de vagas vivenciada no sistema prisional, a superlotação carcerária atenta contra a Constituição Federal e documentos internacionais de proteção ao homem. Por outro lado, a pecúnia não se apresenta como a melhor solução para o cidadão lesado, sendo que esta deve ser subsidiária, antecedendo a ela uma nova forma de remição da pena.

Portanto, essa nova modalidade de remição indica uma nova evolução legislativa e prática para o Direito Penal Brasileiro, que trará benefícios para o condenado e também para o Estado, que ficará isento das indenizações, enfatizando desde já que este novo critério de remição não pode servir de escusa e fundamento para o Estado não investir em melhorias no sistema prisional.

\section{REFERÊNCIAS BIBLIOGRÁFICAS}

BITENCOURT, C. R. Tratado de direito penal: parte geral. 23.ed. rev., ampl. e atual. São Paulo: Saraiva, 2017, vol.1.

BRASIL. Superior Tribunal de Justiça. DIREITO ADMINISTRATIVO. RESPONSABILIDADE OBJETIVA DO ESTADO NO CASO DE SUICíDIO DE DETENTO. Informativo no 520. Relator Ministro Mauro Campbell Marques. Brasília, 02 abr. 2013. Informativo no 520.

CARNELUTTI, F. As misérias do Processo Penal. 3.ed. Leme: CL EDIJUR, 2013.

CNJ. Conselho Nacional de Justiça. Novo diagnóstico de pessoas presas no Brasil. Departamento de Monitoramento e Fiscalização do Sistema Carcerário e do Sistema de Execução de Medidas Socioeducativas - DMF, Brasília/DF, junho de 2014.

DI PIETRO, M. S. Z. Direito Administrativo. 30. ed. rev. atual. e ampl. Rio de Janeiro: Forense, 2017.

GONÇALVES, C. R. Direito Civil Brasileiro: responsabilidade civil. 12.ed. São Paulo: Saraiva, 2017, vol.4.

NUCCl, G. de S. Manual de Processo Penal e Execução Penal. 12. ed. rev. atual. e ampl. Rio de Janeiro: Forense, 2015.

PRADO, L. R. Bem jurídico-penal e constituição. 7.ed. rev. e ampl. São Paulo: Editora Revista dos Tribunais, 2014.

STF. Ministro Barroso propõe remição como forma de indenizar presos em condições degradantes. Notícias STF. Brasília/DF, 06 mai. 2015. Disponível em: <http://www.stf.jus.br/portal/geral/verlmpressao.asp>. Acesso em: 29 mai. 2017 
Repercussão geral. Brasília/DF, 16 fev. 2017. Disponível em: <http://www.stf.jus.br/portal/jurisprudenciaRepercussao/verTeseTema.asp?numTema=365>. Acesso em: 07 ago. 2017.

SUMARIVA, P. Criminologia: teoria e prática. 4.ed. Niterói, RJ: Impetus, 2017. 